\title{
Hemoneumotórax catamenial*
}

\author{
Drs. DAVID LAZO P. ${ }^{1,2}$, ROBERTO GONZÁLEZ L. ${ }^{1,2}$, RAFAEL PRATS M. ${ }^{1,2}$, \\ RAIMUNDO SANTOLAYA C. ${ }^{1,2}$, PATRICIO RODRÍGUEZ D. ${ }^{1,2}$
}

\begin{abstract}
Sección de Cirugía de Tórax, Servicio Médico Quirúrgico Respiratorio, Instituto Nacional del Tórax.
Departamento de Cirugía, Campus Oriente, Universidad de Chile.

Santiago, Chile.
\end{abstract}

\section{Catamenial Hemopneumothorax}

Mujer de 38 años derivada con el diagnóstico de neumotórax espontáneo derecho. Ingresó con tubo pleural, fuga aérea y expansión pulmonar parcial luego de 5 días de tratamiento (Figura 1A). Persistió con expansión pulmonar parcial por lo que se decidió cirugía; se realizó resección del vértice pulmonar (se visualizaron bulas) y pleurodesis mecánica por videotoracoscopía (VTC).

En control al decimoséptimo día se pesquisó neumotórax (Figura 1B). Se reexploró (VTC) sin hallazgos significativos y se realizó pleurodesis con talco. A los 30, 60 y 90 días se mantuvo asintomática.

A los 4 meses consultó por dolor, la radiografía mostró una ocupación pleural líquida y aérea (Figura
1C), la pleurocentesis demostró que la ocupación líquida era un hemotórax. Se reexploró (VTC) y se encontró dos lesiones diafragmáticas solevantadas violáceas de 10 y $5 \mathrm{~mm}$ (Figura 2A) que se resecaron (Figura 2B); bajo una de ellas se encontró una fenestración diafragmática de $10 \mathrm{~mm}$ de diámetro (Figura 2C). El estudio histopatológico intraoperatorio fue compatible con implantes de endometrioma. Después de resecar los implantes, se electrocoaguló sus lechos y se suturó la fenestración. Retrospectivamente la paciente señaló que todas las hospitalizaciones se relacionaron con la menstruación. Evolucionó satisfactoriamente y se derivó a ginecólogo para tratamiento de endometriosis. A 6 meses de seguimiento se encuentra asintomática.

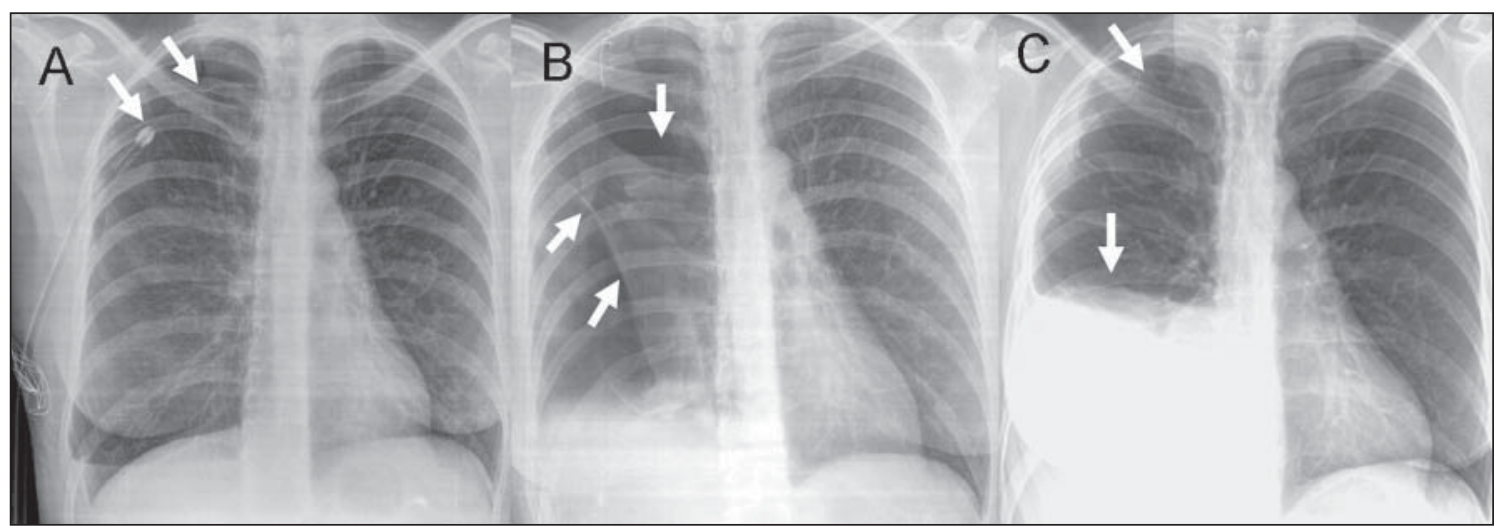

Figura 1. Radiografías de tórax postero-anterior. A. Al ingreso, se observa tubo pleural y persistencia del neumotórax (Flechas). B. A los 17 días, se observa neumotórax y adherencias pleuro-pulmonares (Flechas). C. A los 4 meses, se observa hemoneumotórax (Flechas).

*Recibido el 21 de Septiembre de 2009 y aceptado para publicación el 23 de Octubre de 2009.

Correspondencia: Dr. David Lazo P.

José Manuel Infante 717, Santiago, Chile. Fax: 5625754997

E-mail: dr.david.lazo@gmail.com 


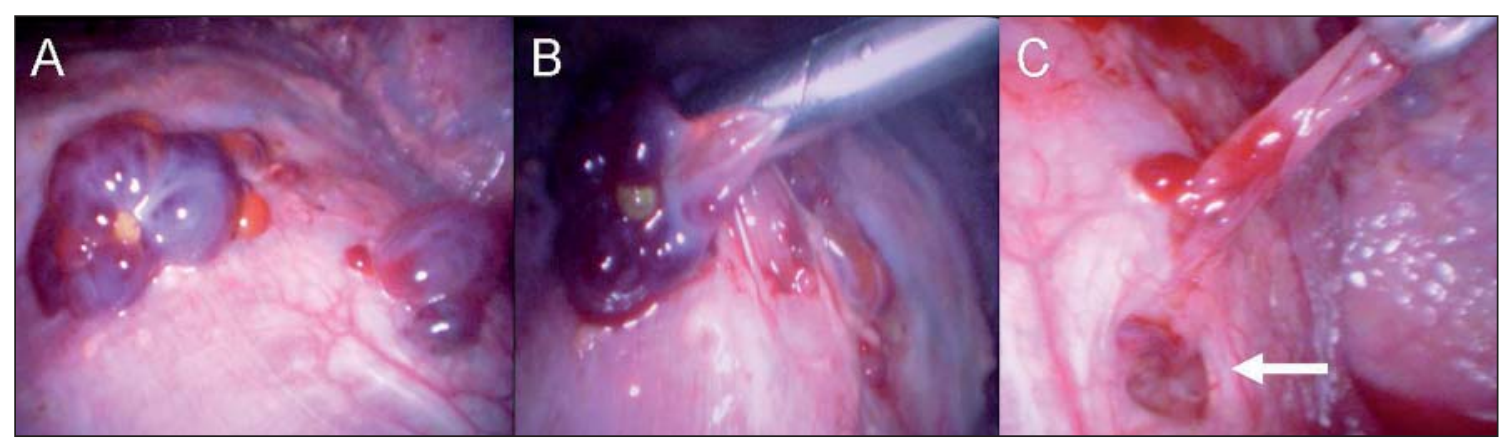

Figura 2. Hallazgos intraoperatorios bajo visión videotoracoscópica. A. Implantes endometriales sobre superficie diafragmática. B. Resección de implantes endometriales. C. Luego del retiro de un implante se observa fenestración diafragmática (Flecha).

\section{Comentario}

Catamenial (del griego katamenia: menstruos; de kata: por; y me: mes): Relacionado con la menstruación.

El neumotórax catamenial es infrecuente y es aquel que ocurre relacionado con la menstruación. Su fisiopatología no está del todo clara, pero aproximadamente entre el $20 \%$ y $40 \%$ se asocian a endometriosis torácica comprobada histológicamente y entre $20 \%$ y $35 \%$ a la presencia de fenestraciones diafragmáticas ${ }^{1,2}$.

Generalmente ocurre en el lado derecho, en mujeres en edad fértil entre la tercera y cuarta década de la vida. En la literatura menos del $20 \%$ de las pacientes con neumotórax catamenial tiene diagnosticada una endometriosis pélvica. El diagnóstico primario es difícil y en algunas series ocurren en promedio hasta 5 episodios antes del tratamiento definitivo ${ }^{1,3}$.

La presentación en una misma paciente como neumotórax y posteriormente como hemoneumotórax es excepcional ${ }^{1,3}$.

\section{Referencias}

1. Korom S, Canyurt H, Missbach A, Schneiter D, Kurrer MO, Haller U, et al. Catamenial pneumothorax revisited: clinical approach and systematic review of the literature. J Thorac Cardiovasc Surg 2004; 128: 502-508.

2. Alifano M, Trisolini R, Cancellieri A, Regnard JF. Thoracic endometriosis: current knowledge. Ann Thorac Surg 2006; 81: 761-769.

3. Ciriaco P, Negri G, Libretti L, Carretta A, Melloni G, Casiraghi M, et al. Surgical treatment of catamenial pneumothorax: a single centre experience. Interact Cardiovasc Thorac Surg 2009; 8: 349-352. 